\title{
Altered Leukotriene Generation in Leukocytes from Cystinotic Children
}

\author{
GUILLEM PINTOS-MORELL, PATRICK SALEM, GENEVIÈVE JEAN, \\ PATRICK NIAUDET, AND JEAN MICHEL MENCIA-HUERTA \\ University Hospital “Germans Trias i Pujol," Badalona, Spain [G.P.-M.]; INSERM U.200, \\ Université Paris-Sud, Clamart, France [P.S.]; INSERM U.192, Hôpital Necker-Enfants \\ Malades, Paris, France [G.J., P.N.]; and Institut Henri Beaufour, Les Ulis, France [J.M.M.-H.]
}

\begin{tabular}{|c|c|}
\hline \multicolumn{2}{|c|}{ ABSTRACT } \\
\hline 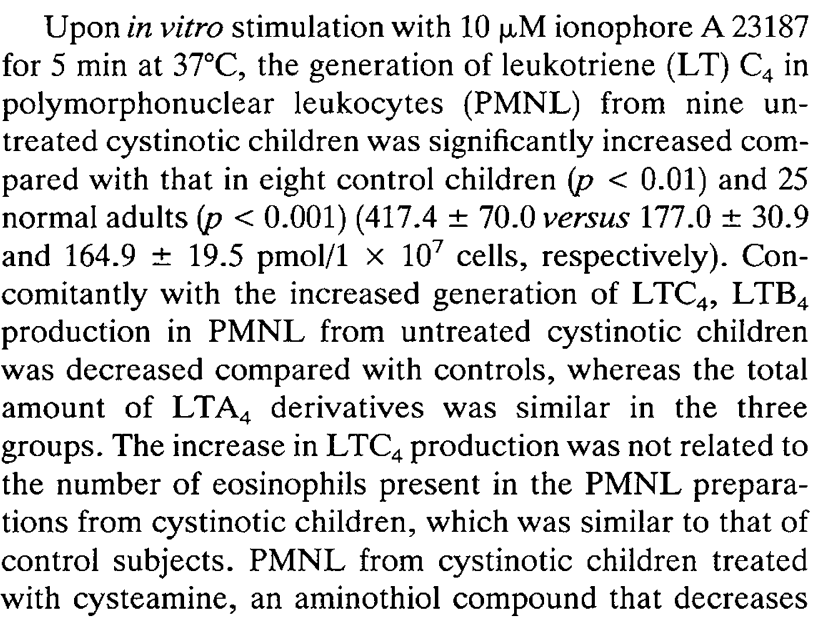 & $\begin{array}{l}\text { the intracellular cystine content, generated smaller } \\
\text { amounts of } \mathrm{LTC}_{4} \text { upon ionophore } \mathrm{A} 23187 \text { stimulation than } \\
\text { PMNL from untreated cystinotic children. In addition, } \\
\text { abrogation of the cysteamine treatment for } 3 \text { or } 4 \mathrm{~d} \text { led to an } \\
\text { increase in } \mathrm{LTC}_{4} \text { production. These findings suggest that } \\
\text { the metabolic abnormalities taking place in infantile cysti- } \\
\text { nosis may favor the biosynthesis of } \mathrm{LTC}_{4} \text { from PMNL. } \\
\text { (Pediatr Res 36: 628-634, 1994) } \\
\text { CDE, cystine dimethylester } \\
\text { GSH, glutathione } \\
\text { HBSS, Hanks' balanced salt solution } \\
\text { LT, leukotriene } \\
\text { PMNL, polymorphonuclear leukocyte } \\
\text { RP-HPLC, reverse-phase HPLC }\end{array}$ \\
\hline
\end{tabular}

LT are lipid mediators derived from arachidonic acid through the 5-lypoxygenase pathway (1). The C-6sulfidopeptide LT, 5(S),6(R)5-hydroxy-6-S-glutathionyl7,9-trans-11,14-cis-eicosatetraenoic acid $\left(\mathbf{L T C}_{4}\right)$ and its derivatives $\mathrm{LTD}_{4}$ and $\mathrm{LTE}_{4}$, are the constituents of the slow-reacting substance of anaphylaxis (2). C-6sulfidopeptide LT are potent inducers of bronchial and ileal smooth muscle contraction (3). They also increase vascular permeability (4) and induce synthesis of prostacyclin by endothelial cells (5) and synthesis of prostaglandin $\mathrm{E}_{2}$ by macrophages (6). Another LT, 5(S),12(R)dihydroxy-6,14-cis-8,10-trans-eicosatetraenoic acid $\left(\mathrm{LTB}_{4}\right)$, is a potent chemotactic factor for human neutrophils and monocytes in vitro (7). $\mathrm{LTB}_{4}$ also increases the expression of $\mathrm{C}_{3} \mathrm{~b}$ receptors and induces lysosomal enzyme release from and aggregation of neutrophils (8).

Received April 5, 1993; accepted February 21, 1994.

Correspondence and reprint requests: Dr. G. Pintos Morell, University Hospital "Germans Trias i Pujol," Department of Pediatrics, 08916 Badalona, Spain.

G.P.M. was supported by grants from the "Comissió Interdepartamental per la Recerca i Innovació Tecnològica” (CIRIT), Generalitat de Catalunya (Spain), and from the PIRMED-Centre National de la Recherche Scientifique (CNRS), France.
The biosynthetic pathway of LT has been elucidated (9). Once released from membrane lipids, arachidonic acid is converted by the 5-lipoxygenase enzyme into 5-hydroperoxy-6-trans-8,11,14-cis-eicosatetraenoic acid, which is transformed into 5,6-oxido-7,9-trans-11,14-ciseicosatetraenoic acid $\left(\mathrm{LTA}_{4}\right)$ by the same enzyme. $\mathrm{LTC}_{4}$ is formed upon the adduction of GSH onto $\mathrm{LTA}_{4}$ by a GSH-S-transferase. $\mathrm{LTA}_{4}$ is also converted into $\mathrm{LTB}_{4}$ by a specific hydrolase or nonenzymatically hydrolyzed primarily into $5(\mathrm{~S}), 12(\mathrm{R})$ - and $5(\mathrm{~S}), 12(\mathrm{~S})$-6-trans-LTB $4^{-}$ diastereoisomers. The latter compounds have also been shown to originate from a myeloperoxidase-dependent metabolism of $\mathrm{LTC}_{4}$ by activated human PMNL (10).

Infantile cystinosis is a recessively inherited metabolic disease characterized by a high intracellular cystine content (11) and the development of renal insufficiency during the first decade of life (12). The primary metabolic defect in cystinosis is a defect of the lysosomal cystine transport (13). Although GSH content is comparable in cystinotic and healthy subjects (14), the presence of several metabolic disturbances in cystinotic cells, such as an accelerated GSH turnover and an increased $\gamma$-glutamyl 
transpeptidase activity $(15,16)$, are considered to be secondary to the increased cystine content.

Cysteamine ( $\beta$-mercaptoethylamine), which decreases the intracellular cystine content in vitro and in vivo (17), has proven its efficiency in the treatment of cystinosis by improving growth and maintaining glomerular function in cystinotic children (18).

Because of the direct implication of cyst(e)ine and GSH in $\mathrm{LTC}_{4}$ synthesis, we investigated the possible relationship between the intracellular cystine content and $\mathrm{LTC}_{4}$ generation in PMNL from cystinosis patients. This was performed by comparing ionophore A 23187-induced generation of LT from PMNL of cystinotic children with that of control subjects and heterozygotes.

\section{METHODS}

Patients and controls. Eighteen cystinotic children, aged 2 to $10 \mathrm{y}$, before end-stage renal failure and presenting a glomerular filtration rate greater than $30 \mathrm{~mL} / \mathrm{min} / 1.73 \mathrm{~m}^{2}$ were selected. Kidney-transplanted cystinotic children were not included because they were receiving immunosuppressive therapy. All the patients, except two, were receiving cysteamine treatment at the beginning of the study. Three other groups were also studied: the first consisted of eight children aged 3 to $11 \mathrm{y}$ [three presenting chronic obstructive uropathy with mild renal insufficiency (glomerular filtration rate $>30 \mathrm{~mL} / \mathrm{min} / 1.73 \mathrm{~m}^{2}$ ) and five normal children]. Because in these subjects no difference in the ionophore A 23187-induced generation of the various $\mathrm{LTA}_{4}$ metabolites was observed, the results were analyzed as those of an homogeneous group. The second group included 10 adult cystinotic heterozygotes, and the third consisted of 25 healthy adult blood donors. All patients and controls were free of any sign of infection at the time of the experiments. In the case of cysteamine-treated children, blood was collected $6 \mathrm{~h}$ after the last ingestion of the drug. In seven cystinosis patients, experiments were performed under cysteamine, and 3 to $4 \mathrm{~d}$ after interruption of treatment. Informed consent was obtained from the parents of the cystinotic and control children and from the adults before collection of blood samples.

Cell separation procedures. Ten-mL blood samples were collected using heparin $(10 \mathrm{U} / \mathrm{mL})$ (Liquemine, Roche, Basel, Switzerland) as anticoagulant. PMNL were isolated upon dextran sedimentation, Ficoll separation, and erythrocyte lysis with ammonium chloride as previously described (19). The cells were finally resuspended in $\mathrm{Ca}^{2+}$ - and $\mathrm{Mg}^{2+}$-containing $\mathrm{HBSS}$ without phenol red (Eurobio, Paris, France) at a final concentration of $1.1 \times$ $10^{7}$ cells/mL. PMNL purity averaged $97-98 \%$ and viability was greater than $99 \%$ as assessed by the trypan blue exclusion method. These cell populations contained mostly neutrophils and less than $10 \%$ eosinophils, as determined on smears obtained with a cytocentrifuge (Cytospin 2, Shandon, Runcorn, England) and stained with May-Grunwald-Giemsa.
Cell stimulation. Replicate tubes containing $5 \times 10^{6}$ PMNL in $450 \mu \mathrm{L}$ of HBSS were preincubated at $37^{\circ} \mathrm{C}$ for 5 min. A sufficient amount of calcium ionophore A 23187 (Calbiochem-Boehring Corp., La Jolla, CA) in $50 \mu \mathrm{L}$ of HBSS was then added to reach a final concentration of 10 $\mu \mathrm{M}$. After $5 \mathrm{~min}$ of incubation at $37^{\circ} \mathrm{C}$, the reaction was stopped upon addition of $500 \mu \mathrm{L}$ methanol. This incubation period with this concentration of Ionophore were determined to be optimal for LT generation. In preliminary experiments, the dose-response to ionophore $\mathrm{A}$ 23187 and time course for LT generation were shown to be similar for PMNL from all groups of subjects (data not shown). The samples were centrifuged at $500 \times g$ for 10 min, and the supernatants collected and stored at $-80^{\circ} \mathrm{C}$ under nitrogen.

In nine different experiments, PMNL from normal adults $\left(1.1 \times 10^{7}\right.$ cells $\left./ \mathrm{mL}\right)$ were suspended in $\mathrm{Ca}^{2+}$ - and $\mathrm{Mg}^{2+}$-free HBSS, pH 7.0 , and aliquots $(500 \mu \mathrm{L})$ were transferred into tubes containing a sufficient amount of CDE to reach a final concentration of $0.25 \mathrm{mM}(20)$. Experiments were performed in parallel with tubes containing CDE and without CDE. CDE was introduced into the tubes as a methanol solution and dried under nitrogen before the cells were added. Then, the cells were incubated for $1 \mathrm{~h}$ at $37^{\circ} \mathrm{C}$ with gentle shaking, washed twice by centrifugation in $\mathrm{Ca}^{2+}$ - and $\mathrm{Mg}^{2+}$-free $\mathrm{HBSS}$ for $5 \mathrm{~min}$ at $500 \times g$, counted, and finally resuspended at a concentration of $5 \times 10^{6}$ PMNL in $450 \mu \mathrm{L}$ of $\mathrm{Ca}^{2+}$ - and $\mathrm{Mg}^{2+}$-containing HBSS before ionophore A 23187 stimulation as described above. Cell viability was not affected by the CDE treatment as assessed by the trypan blue exclusion method.

LT analysis. The samples from stimulated and unstimulated PMNL were analyzed by RP-HPLC as previously described (21). RP-HPLC was carried out with a Waters apparatus (Waters Associates, Millipore Corp., Milford, MA) using a $\mu$ Bondapak C18 column $(4.6 \times 250 \mathrm{~mm})$ (Waters) eluted at a flow rate of $1 \mathrm{~mL} / \mathrm{min}$ with methanol:water:acetic acid (60:40:0.1, vol/vol; pH 5.6) as solvent. Five-hundred- $\mu \mathrm{L}$ samples were injected, and the elution was monitored at $280 \mathrm{~nm}$ using a 440 Waters spectrophotometer. $\mathrm{LTC}_{4}$, 6-trans-LTB 4 diastereoisomers, and $\mathrm{LTB}_{4}$ were quantified by integration of the UV absorbance peak according to a standard curve established with known amounts of authentic standards. In selected experiments, 1-min fractions were collected and dried under vacuum. The dry residues were resuspended

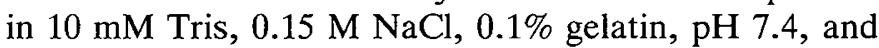
the samples were assayed for C-6-sulfidopeptide LT content using an RIA. Synthetic $\mathrm{LTC}_{4}$ and rabbit antibodies against $\mathrm{LTC}_{4}$ were a gift from Dr. Rokach (Merck Frosst, Montreal, Canada). $\left[{ }^{3} \mathrm{H}\right] \mathrm{LTC}_{4}$ was purchased from New England Nuclear (Paris, France).

Intracellular cystine assay. Leukocytes were prepared by mixing fresh heparinized blood with an equal volume of a solution containing $3 \mathrm{~g}$ of dextran, $2.1 \mathrm{~g}$ of dextrose, $0.33 \mathrm{~g}$ of sodium citrate, and $0.11 \mathrm{~g}$ of anhydrous citric acid in $100 \mathrm{~mL}$ of $0.15 \mathrm{~N} \mathrm{NaCl}$. After sedimentation for 45 
min at room temperature, the supernatant was removed and centrifuged at $450 \times g$ for $10 \mathrm{~min}$. The leukocyte pellet was resuspended in $3.2 \mathrm{~mL}$ of $0.22 \% \mathrm{NaCl}$ for $90 \mathrm{~s}$ to lyse the remaining erythrocytes, and isotonicity was then restored by the addition of $0.8 \mathrm{~mL}$ of $3.6 \mathrm{NaCl}$. The cells were sedimented by centrifugation at $450 \times g$ for 5 $\mathrm{min}$, and the pellet was washed twice with $0.15 \mathrm{~N} \mathrm{NaCl}$. Finally, the pellet was sonicated in $0.3 \mathrm{~mL}$ of distilled water and mixed with $0.1 \mathrm{~mL}$ of $12 \%$ sulfosalicylic acid. Cystine determinations were performed on the acidsoluble fraction by means of the cystine binding protein assay (22). The protein content was measured in the acid-insoluble fraction using the Folin-Lowry method.

Statistical analysis. Results are expressed as means \pm SEM of the indicated number of experiments. Significance was assessed by the paired and unpaired $t$ test, the nonparametric Wilcoxon signed-rank test and the linear regression test.

\section{RESULTS}

Ionophore-induced generation of LT from PMNL from healthy and cystinotic children. RP-HPLC analysis of supernatants from ionophore-stimulated PMNL of cystinotic children resulted in elution patterns similar to those from PMNL of control adults and children (Fig. 1). Four peaks of 280-nm absorbing material corresponding to the retention time of authentic $\mathrm{LTC}_{4}, 5(\mathrm{~S}), 12(\mathrm{R})$ - and 5(S),12(S)-6-trans- $\mathrm{LTB}_{4}$ diastereoisomers, and $\mathrm{LTB}_{4}$ were detected. However, the amount of UV-absorbing

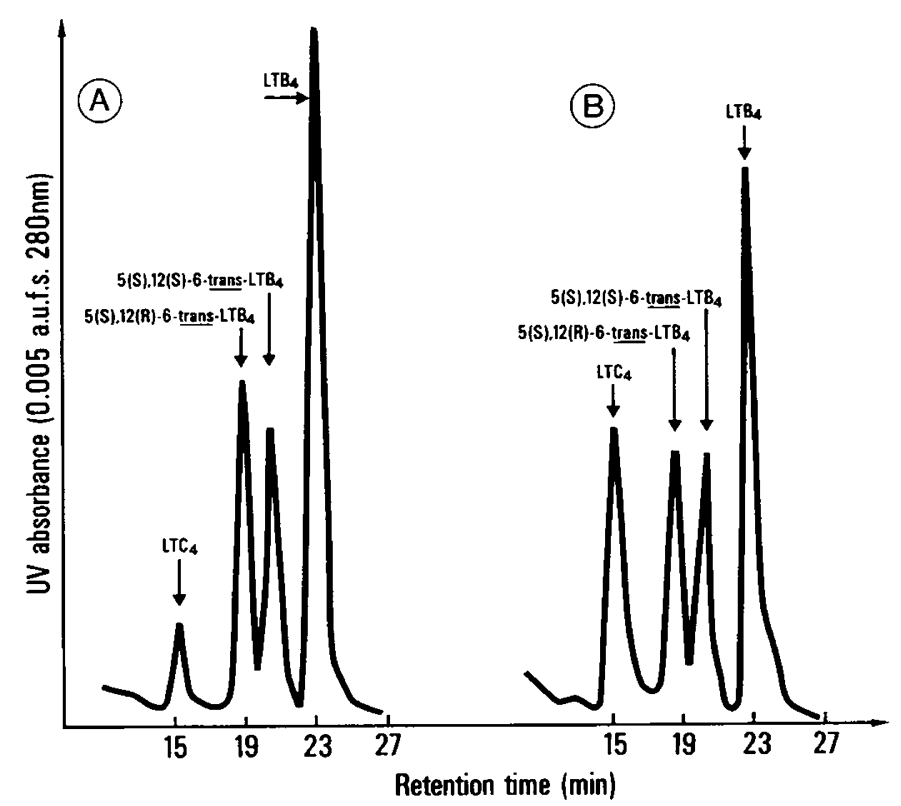

Figure 1. Representative RP-HPLC elution patterns of the products generated from ionophore A 23187-stimulated PMNL from control adults $(n=25)$ and control children $(n=8)(A)$ and cystinotic children $(B)$. The cells were preincubated for $5 \mathrm{~min}$ at $37^{\circ} \mathrm{C}$ and then stimulated with $10 \mu \mathrm{M}$ ionophore for an additional $5 \mathrm{~min}$. RP-HPLC was carried out using a $\mu$ Bondapak $\mathrm{C} 18$ column eluted at $1 \mathrm{~mL} / \mathrm{min}$ with methanol:water:acetic acid (60:40:0.1, pH 5.6). The elution was monitored at 280 $\mathrm{nm}$, and the arrows indicate the retention times of authentic standards. a.u.f.s., absorbance unit full scale. material exhibiting the retention time of $\mathrm{LTC}_{4}$ was markedly higher in the supernatants of ionophore-stimulated PMNL from cystinotic patients (Fig. 1B) compared with control adults and control children (Fig. $1 A$ ). In addition, a slight decrease in the amount of the product eluting with the retention time of $\mathrm{LTB}_{4}$ was noted. In contrast, no marked variations in the amounts of products eluting with the retention times of the 6-trans-LTB ${ }_{4}$ diastereoisomers were observed. No UV-absorbing peak was observed when the supernatants of unstimulated PMNL from either cystinotic or control subjects were analyzed by RPHPLC.

Fractions collected during RP-HPLC of the supernatants from ionophore A 23187-stimulated PMNL of cystinotic children were assessed for C-6-sulfidopeptide LT. As presented in Figure 2, only the UV-absorbing material exhibiting the retention time of authentic $\mathrm{LTC}_{4}$ was immunoreactive. In three experiments, the amounts of $\mathrm{LTC}_{4}$ quantitated by integration of UV absorbance were similar to those obtained using RIA: 245.7 and 237.5, 187.6 , and 177.5 , and 280.0 and $255.9 \mathrm{pmol} / 1 \times 10^{7}$ cells, respectively. The correlation coefficient between the two methods was 0.996; thus, the use of the RIA was discontinued.

The amount of $\mathrm{LTA}_{4}$ metabolites, namely, $\mathrm{LTC}_{4}$, 6-trans- $\mathrm{LTB}_{4}$ diasteroisomers, and $\mathrm{LTB}_{4}$ in the supernatants of ionophore-stimulated PMNL from control adults and control children, cystinotic adult heterozygotes, and cystinotic children with and without cysteamine treatment was measured by integration of the respective UVabsorbing peak during RP-HPLC (Table 1). For seven of the nine untreated cystinotic children, cysteamine admin-

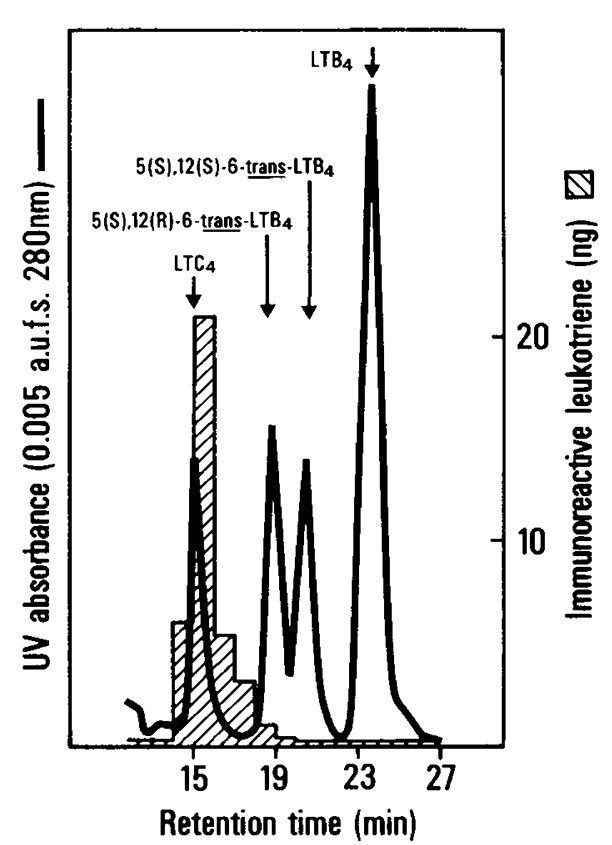

Figure 2. RP-HPLC elution pattern of the products generated from PMNL of a cystinotic child. Same experimental protocol as in Figure 1, except that 1-min fractions were collected and assayed for crossreactivity in an RIA for C-6-sulfidopeptide LT. One experiment representative of three. 
Table 1. LT production in ionophore A 23187-stimulated PMNL*

\begin{tabular}{|c|c|c|c|c|c|}
\hline & \multicolumn{2}{|c|}{ Controls } & \multirow{2}{*}{$\begin{array}{l}\text { Adult cystinotic } \\
\text { heterozygotes }\end{array}$} & \multirow{2}{*}{$\begin{array}{l}\text { Cysteamine-treated } \\
\text { cystinotic children }\end{array}$} & \multirow{2}{*}{$\begin{array}{l}\text { Untreated cystinotic } \\
\text { children }\end{array}$} \\
\hline & Adults & Children & & & \\
\hline$\overline{\text { Numb }}$ & 25 & 8 & 10 & 18 & 9 \\
\hline $\mathrm{LTC}_{4}$ & $164.9 \pm 19.5(9.8)$ & $177.0 \pm 30.9(9.7)$ & $137.6 \pm 32.1(9.9)$ & $242.3 \pm 16.2 \dagger(15.4)$ & $417.4 \pm 70.0 \ddagger(25.4)$ \\
\hline $5(\mathrm{~S}), 12(\mathrm{R})-6$-trans- $\mathrm{LTB}_{4}$ & $275.5 \pm 14.2(16.3)$ & $260.0 \pm 23.2(14.2)$ & $240.0 \pm 27.8(17.2)$ & $248.2 \pm 25.5(15.8)$ & $248.9 \pm 29.8(15.1)$ \\
\hline $5(\mathrm{~S}), 12(\mathrm{~S})-6$-trans- $\mathrm{LTB}_{4}$ & $261.0 \pm 13.7(15.5)$ & $242.3 \pm 27.1(13.3)$ & $234.9 \pm 22.2(16.9)$ & $243.2 \pm 28.7(15.4)$ & $210.1 \pm 28.9(12.8)$ \\
\hline $\mathrm{LTB}_{4}$ & $985.7 \pm 56.4(58.4)$ & $1174.4 \pm 120.6(62.8)$ & $779.2 \pm 61.1(56.0)$ & $839.6 \pm 69.2(63.4)$ & $767.6 \pm 72.1 \dagger(46.7)$ \\
\hline Total LTA $_{4}$ metabolites & $1687.1 \pm 80.3(100.0)$ & $1826.7 \pm 153.1(100.0)$ & $1391.7 \pm 84.0 \dagger(100.0)$ & $1573.3 \pm 98.3(100.0)$ & $1644.0 \pm 82.7(100.0)$ \\
\hline
\end{tabular}

${ }^{*}$ A total of $5 \times 10^{6}$ PMNL from control adults and control children, adult cystinotic heterozygotes, and cysteamine-treated and untreated cystinotic children were stimulated with $10 \mu \mathrm{M}$ ionophore A 23187 for $5 \mathrm{~min}$ at $37^{\circ} \mathrm{C}$. LT were quantitated by integration of the UV absorbance peak during RP-HPLC. Values are expressed as mean \pm SEM pmol/1 $\times 10^{7}$ cells, and the numbers of parentheses indicate the percentage of each product with respect to the total amount of $\mathrm{LTA}_{4}$ metabolites. Significance of absolute values was assessed by the unpaired $t$ test with respect to control children.

$\dagger p<0.05$.

$\ddagger p<0.01$.

istration was interrupted for 3 to $4 \mathrm{~d}$ before the experiments. Upon ionophore stimulation, the total amounts of $\mathrm{LTA}_{4}$ metabolites generated were lower in PMNL from adult cystinotic heterozygotes compared with the other four cell populations. The amount of $\mathrm{LTC}_{4}$ with respect to the total amount of $\mathrm{LTA}_{4}$ derivatives generated from PMNL was higher in cysteamine-untreated cystinotic children $(25.4 \%)$ than in cysteamine-treated cystinotic children $(15.4 \%)$, cystinotic heterozygotes $(9.9 \%)$, control children $(9.7 \%)$, and normal adults $(9.8 \%)$. The increased $\mathrm{LTC}_{4}$ production in PMNL from untreated cystinotic children was associated with a decrease in the generation of $\mathrm{LTB}_{4}$, which was significantly $(p<0.05)$ lower than that in children and adult controls.

Role of eosinophils in generation of $\mathrm{LTC}_{4}$ from PMNL. Human eosinophils release large amounts of $\mathrm{LTC}_{4}(23)$. However, the possibility that the different release of $\mathrm{LTC}_{4}$ in the various PMNL populations demonstrated in Table 1 was merely due to the variation in the number of eosinophils is excluded, because the percentages of this cell type were similar in the PMNL populations from control adults $(5.5 \pm 4.5 \%)$ and control children $(5.5 \pm$ $2.0 \%)$, adult cystinotic heterozygotes $(4.5 \pm 2.9 \%)$, and cysteamine-treated $(6.8 \pm 3.5 \%)$ and untreated cystinotic children $(6.9 \pm 4.1 \%)$. In addition, statistical analysis showed no correlation between the amounts of $\mathrm{LTC}_{4}$ generated upon ionophore A 23187 stimulation of PMNL from cystinotic children and the number of eosinophils present in the cell preparation $(r=0.335 ; p>0.10, n=$ 27).

Role of intracellular cystine content in generation of $L_{T C C_{4}}$ from PMNL. In seven patients, the ionophore A 23187 induced generation of LT from PMNL was assessed during cysteamine treatment and 3 to $4 \mathrm{~d}$ after withdrawal of the drug (Table 2). In four of the seven patients (patients 1,2, 4, and 7), a marked increase in the ionophore A 23187 -induced LTC $_{4}$ production was observed with the interruption of the drug, whereas in the three other patients (patients 3,5, and 6) no significant difference was observed. Notably, the four patients presenting an increase in ionophore-induced $\mathrm{LTC}_{4}$ production were also those presenting the highest increment in cystine content after cysteamine withdrawal for 3 to $4 \mathrm{~d}$. In addition, the increment in $\mathrm{LTC}_{4}$ production and cystine content were highly correlated $(p=0.004)$. In these experiments, the increase in $\mathrm{LTC}_{4}$ generation upon stimulation of PMNL from untreated patients also appeared to be concomitant with a decrease in $\mathrm{LTB}_{4}$ production. In contrast, the amounts of 6-trans- $\mathrm{LTB}_{4}$ diastereoisomers were unchanged, and the total amount of $\mathrm{LTA}_{4}$ metabolites produced was similar before $(1701.0 \pm 193.0 \mathrm{pmol} / 1$ $\times 10^{7}$ cells $)$ and after $\left(1629.3 \pm 98.9 \mathrm{pmol} / 1 \times 10^{7}\right.$ cells $)$ interruption of the cysteamine treatment.

$\mathrm{CDE}$ has been shown to increase several times the intracellular cystine content (20). To investigate the possible relationship between the intracellular cystine content and $\mathrm{LTC}_{4}$ production, PMNL from normal adults were incubated for $1 \mathrm{~h}$ in the presence of $0.25 \mathrm{mM} \mathrm{CDE}$

Table 2. Cystine content (Cyst) and $\mathrm{LTC}_{4}$ generation from ionophore-stimulated PMNL from cystinotic children*

\begin{tabular}{|c|c|c|c|c|c|c|}
\hline & \multicolumn{4}{|c|}{ Cysteamine treatment } & \multirow[b]{3}{*}{$\Delta \mathrm{LTC}_{4}$} & \multirow[b]{3}{*}{$\Delta$ Cyst } \\
\hline & \multicolumn{2}{|c|}{+} & \multicolumn{2}{|c|}{-} & & \\
\hline & $\mathrm{LTC}_{4}$ & Cyst & $\mathrm{LTC}_{4}$ & Cyst & & \\
\hline \multicolumn{7}{|c|}{ Patient } \\
\hline 1 & 182.4 & 2.0 & 435.2 & 5.1 & 252.8 & 3.1 \\
\hline 2 & 336.0 & 1.6 & 684.8 & 7.1 & 348.8 & 5.5 \\
\hline 3 & 547.2 & 2.4 & 454.4 & 4.3 & -92.8 & 2.0 \\
\hline 4 & 150.4 & 1.6 & 326.4 & 5.3 & 176.0 & 3.7 \\
\hline 5 & 156.8 & 0.6 & 166.4 & 1.3 & 9.6 & 0.7 \\
\hline 6 & 211.2 & 3.4 & 185.6 & 4.2 & -25.6 & 0.7 \\
\hline 7 & 265.6 & 0.9 & 800.0 & 6.7 & 534.4 & 5.8 \\
\hline Mean & 264.7 & 1.8 & 436.1 & 4.9 & & \\
\hline SEM & 53.3 & 0.3 & 90.2 & 0.7 & & \\
\hline$r$ & \multicolumn{2}{|c|}{0.239} & \multicolumn{2}{|c|}{0.835} & \multicolumn{2}{|c|}{0.910} \\
\hline$p$ & \multicolumn{2}{|c|}{0.606} & \multicolumn{2}{|c|}{0.019} & \multicolumn{2}{|c|}{0.004} \\
\hline
\end{tabular}

* A total of $5 \times 10^{6}$ PMNL obtained from seven cystinotic children both during $(+)$ and 3 to $4 \mathrm{~d}$ after interruption $(-)$ of treatment with cysteamine were stimulated with $10 \mu \mathrm{M}$ ionophore $\mathrm{A} 23187$ for $5 \mathrm{~min}$ at $37^{\circ} \mathrm{C}$. LT were quantitated by integration of the UV absorbance peak during RP-HPLC, and results are expressed as means \pm SEM pmol $\mathrm{LTC}_{4} / 1 \times 10^{7}$ cells. Cystine was measured by a cystine binding assay as defined in "Methods," and results are expressed as nmol half cystine/mg protein. $\Delta$ represents the difference between $\mathrm{LTC}_{4}$ generation and cystine content after drug withdrawal and the values obtained during treatment. 
before ionophore A 23187 stimulation. As presented in Table 3, incubation of PMNL with CDE led to a significant $(p<0.05)$ increase in $\mathrm{LTC}_{4}$ generation after ionophore stimulation compared with $\mathrm{LTC}_{4}$ generation in untreated PMNL. In contrast, the production of the 6-trans- $\mathrm{LTB}_{4}$ diastereoisomers and $\mathrm{LTB}_{4}$ as well as the total amount of $\mathrm{LTA}_{4}$ metabolites were not significantly altered in CDE-treated PMNL compared with untreated ones. In these experiments, the cystine content was 0.29 \pm 0.07 and $3.47 \pm 0.67 \mathrm{nmol}$ half cystine $/ \mathrm{mg}$ protein in control and CDE-treated PMNL, respectively.

Finally, the intracellular cystine content and the amounts of $\mathrm{LTC}_{4}$ generated upon ionophore stimulation were measured in PMNL preparations from 10 cysteamine-treated cystinotic children (Table 4). In these patients, the intracellular cystine content was 3 to 17 times greater than normal values, which were less than $0.2 \mathrm{nmol}$ half cystine/mg protein. However, no correlation $(r=0.239)$ was observed between the intracellular cystine content and $\mathrm{LTC}_{4}$ generation in these experiments.

\section{DISCUSSION}

Ionophore-stimulated PMNL from cystinotic children generated increased amounts of $\mathrm{LTC}_{4}$ compared with those from control children, control adults, and adult cystinotic heterozygotes. $\mathrm{LTC}_{4}$ generated from cystinotic PMNL upon ionophore stimulation was identified by its retention time during RP-HPLC and the quantitative correspondence between RIA measurement and integration of the UV absorbance peak.

The total amounts of $\mathrm{LTA}_{4}$ metabolites, namely $\mathrm{LTC}_{4}$, 6-trans $-\mathrm{LTB}_{4}$ diastereoisomers, and $\mathrm{LTB}_{4}$ generated from ionophore-stimulated PMNL from cystinotic children were similar to those generated from children and adult control PMNL. However, upon ionophore stimulation of PMNL from cystinotic children, a significant increase in the amount of $\mathrm{LTC}_{4}$ and a concomitant decrease in the production of $\mathrm{LTB}_{4}$ were observed. Thus, increased metabolism of $\mathrm{LTA}_{4}$ via the GSH-S-transferase pathway appeared to be responsible for the increased $\mathrm{LTC}_{4}$ generation in PMNL from cystinotic children. In

Table 3. Effect of incubation of PMNL with $C D E$ on ionophore-induced production of $L T^{*}$

\begin{tabular}{|c|c|c|}
\hline & Control PMNL & CDE-treated PMNL \\
\hline $\mathrm{LTC}_{4}$ & $78.6 \pm 15.4(7.9)$ & $120.2 \pm 17.5(11.5) \dagger$ \\
\hline $5(\mathrm{~S}), 12(\mathrm{R})-6$-trans $-\mathrm{LTB}_{4}$ & $167.1 \pm 10.5(16.8)$ & $178.5 \pm 13.2(17.0)$ \\
\hline $5(\mathrm{~S}), 12(\mathrm{~S})-6-$ trans $-\mathrm{LTB}_{4}$ & $150.4 \pm 10.4(15.1)$ & $163.9 \pm 12.8(15.7)$ \\
\hline $\mathrm{LTB}_{4}$ & $597.1 \pm 37.4(60.1)$ & $584.2 \pm 32.7(55.8)$ \\
\hline Total LTA 4 metabolites & $993.2 \pm 62.7(100.0)$ & $1046.8 \pm 60.5(100.0)$ \\
\hline
\end{tabular}

${ }^{*}$ Replicate tubes containing $5 \times 10^{6} \mathrm{PMNL}$ from adult controls were incubated for $1 \mathrm{~h}$ at $37^{\circ} \mathrm{C}$ in the presence or absence of $0.25 \mathrm{mM} \mathrm{CDE}$ from ionophore stimulation for $5 \mathrm{~min}$. LT were quantitated by integration of the UV absorbance peak during RP-HPLC. Values are expressed as means $\pm \mathrm{SEM}$ pmol/ $1 \times 10^{7}$ cells of nine experiments and values in parentheses are the percentage of each product with respect to the total amount of $\mathrm{LTA}_{4}$ metabolites.

$\dagger p<0.05$. Significance was assessed by the Wilcoxon sign-rank test.
Table 4. Intracellular cystine content and $\mathrm{LTC}_{4}$ generation from PMNL of cysteamine-treated cystinotic children*

\begin{tabular}{ccc}
\hline Patient & $\begin{array}{c}\text { Intracellular cystine } \\
\text { (nmol half cystine/mg protein) }\end{array}$ & $\begin{array}{c}\text { LTC }_{4} \\
\text { (pmol/1 } \times 10^{7} \text { cells) }\end{array}$ \\
\hline 1 & 0.57 & $169.6(8.7)$ \\
2 & 0.61 & $547.2(28.0)$ \\
3 & 0.91 & $214.4(17.0)$ \\
4 & 3.43 & $211.2(8.2)$ \\
5 & 1.60 & $332.8(20.3)$ \\
6 & 1.60 & $118.4(7.6)$ \\
7 & 0.56 & $230.4(13.6)$ \\
8 & 2.34 & $275.2(15.0)$ \\
9 & 1.30 & $166.4(12.3)$ \\
10 & 1.70 & $342.4(19.5)$ \\
\hline
\end{tabular}

* Intracellular cystine content was measured using a cystine binding assay as described in "Methods" (normal values: $0-0.2 \mathrm{nmol}$ half cystine/mg protein). $\mathrm{LTC}_{4}$ generated from PMNL upon ionophore stimulation was quantitated by integration of the UV absorbance peak during RP-HPLC. The numbers in parentheses indicate the percentage of $\mathrm{LTC}_{4}$ with respect to the total amount of $\mathrm{LTA}_{4}$ metabolites.

these experiments, the amounts of two of the nonenzymatic degradation products of $\mathrm{LTA}_{4}$, namely 5,6dihydroxy-7,9-trans-11,14-cis-eicosatetraenoic acid diastereoisomers $(8,9)$, only accounted for less than $2 \%$ of the total $\mathrm{LTA}_{4}$ metabolites. The addition of catalase (500-1000 U) during stimulation did not modify the RPHPLC elution pattern of the LT generated from PMNL of cystinotic children and controls (data not shown). This excludes the possibility that the increase in $\mathrm{LTC}_{4}$ production was due to less efficient myeloperoxydasedependent LT catabolism (10) in PMNL from cystinotic children than in control subjects.

Calcium ionophore stimulation of phospholipase $\mathrm{A}$ has no preferential effects per se on the different arachidonic metabolites, but it depends on the particular cell type. Ionophore-stimulated human neutrophils preferentially produce $\mathrm{LTB}_{4}(7)$, and eosinophils have been shown to release significant amounts of $\mathrm{LTC}_{4}(23)$. However, in the present study, no difference in the percentage of eosinophils was noted between the various PMNL preparations, indicating that the increase in $\mathrm{LTC}_{4}$ production in PMNL from cystinotic children was not related to a variation in the composition of the cell populations studied. In addition, there was no correlation between the amount of $\mathrm{LTC}_{4}$ generated and the number of eosinophils present in the PMNL preparations from cystinotic children. Our study, however, does not exclude the possibility that the alteration in $\mathrm{LTC}_{4}$ generation is related to a modification of the eosinophil response. Unfortunately, purification of eosinophils could not be performed due to the small volume of blood that can be obtained safely from children. Only the comparison of the response of purified cell populations from cystinotic and control subjects will permit us to eventually ascribe the observed alterations with a defined cell type. An alternative possibility, not ruled out in our study, is that cystinotic eosinophils could generate drastically enhanced quantities of LTC $_{4}$ and that a second biochemical defect exists in the neutrophils, attenuating $\mathrm{LTB}_{4}$ production. 
The major biochemical alteration of cells from cystinotic children is a defect of the lysosomal cystine transport (13). The association of increased uptake (24) and reduction rates of cystine (25) as well as increased $\gamma$-glutamyl transpeptidase activity and accelerated GSH turnover $(15,16)$ are considered to be secondary findings. Also, an increase in GSH synthetase activity has been shown in lag and early growth phases of cystinotic cells, and it was not reflected in increased GSH content (26). Cysteamine has been shown to deplete transiently the intracellular cystine content in leukocytes from cystinotic children (27). Accordingly, $\mathrm{LTC}_{4}$ production from PMNL of cysteamine-treated cystinotic children was markedly lower than in untreated cystinotic children and patients for whom the treatment was interrupted. In four of seven cystinotic children studied with and without cysteamine, drug withdrawal led to a further enhancement of $\mathrm{LTC}_{4}$ generation without alteration of the total production of $\mathrm{LTA}_{4}$ metabolites. These data suggest that elevated intracellular cystine content is involved in the increase in $\mathrm{LTC}_{4}$ production. Although most cystine accumulation occurs in the lysosome while the synthesis of $\mathrm{LTC}_{4}$ takes place in the cytoplasm, the presence of an alternative nonsaturable transmembrane route for cystine transport from the lysosome to the cytoplasm demonstrated in L-929 fibroblasts (28) supports this possibility (Fig. 3). Accordingly, cystinotic cells, mainly

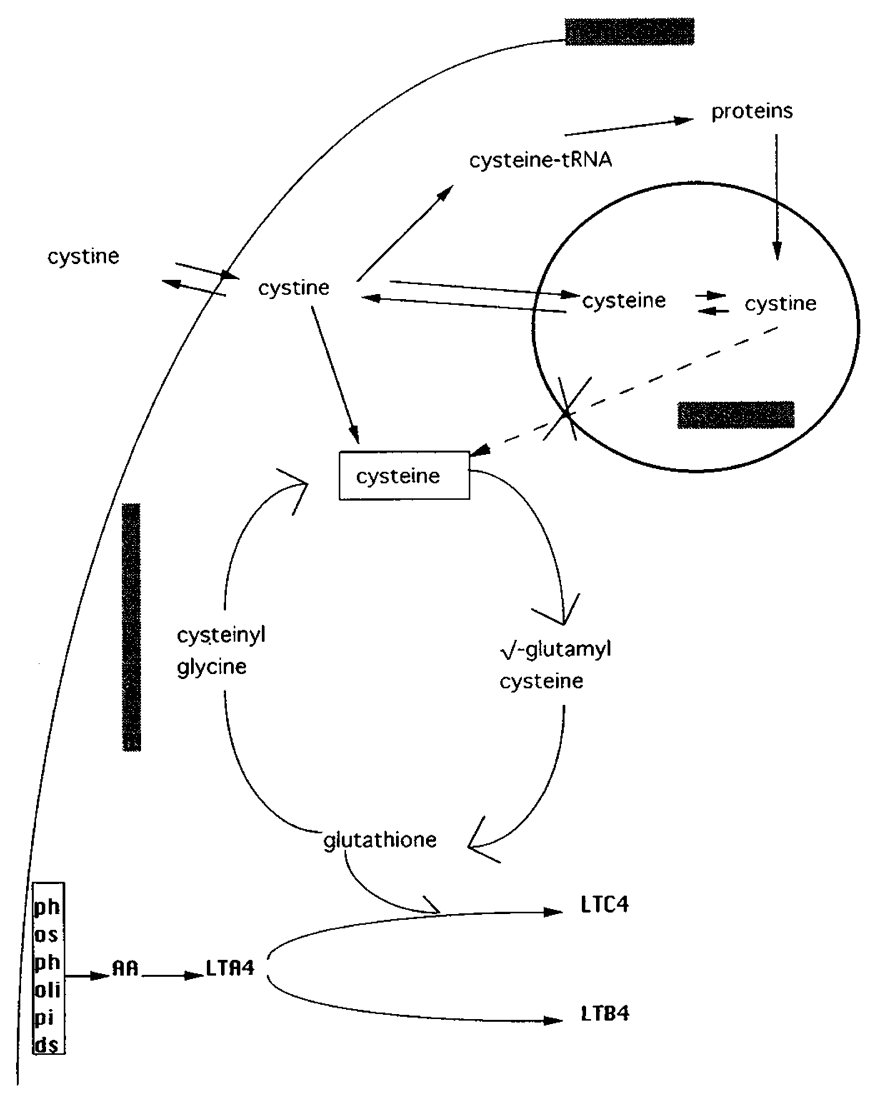

Figure 3. Hypothetical relationship between cystine and $\mathrm{LTC}_{4}$ synthesis in cystinotic cells. The broken arrow indicates that at high intralysosomal cystine concentrations some cystine may exit the lysosome through a nonsaturable mechanism. granulocytes and monocytes, present multiple alterations of diverse biologic responses $(29,30)$. This hypothesis was further strengthened by our experiments showing that PMNL previously loaded with CDE generated, when stimulated by ionophore A 23187, higher amounts of $\mathrm{LTC}_{4}(53 \%$ increase) than untreated PMNL.

The lack of correlation between the intracellular cystine content and the amounts of $\mathrm{LTC}_{4}$ observed in cysteamine-treated cystinosis patients must be accepted with caution because of the possible drug interactions with the SH-dependent enzymes of the 5-lipoxygenase pathway and with GSH (31).

PMNL from adult cystinotic heterozygotes, which present an intracellular cystine content close to that of cysteamine-treated children (32), generated an amount of $\mathrm{LTC}_{4}$ similar to that generated by PMNL of control children and adults. These results suggest that the cystine content is not the only reason for the increase in $\mathrm{LTC}_{4}$ production of PMNL from cystinotic children and that other biochemical alterations present in the complete genetic defect may play a role. These results are in agreement with a previous report showing that PMNL from cystinotic children exhibit an increased oxidative burst upon phorbol-myristate-acetate and formylmethionyl-leucyl-phenylalanine peptide stimulation that is not correlated with the intracellular cystine content (29).

Additional studies on GSH-S-transferase activity and GSH turnover in purified populations of neutrophils and eosinophils from cystinotic children may provide a better understanding of the alteration of LT production presently demonstrated in mixed granulocyte preparations. $\mathrm{LTC}_{4}$ produces vasoconstriction, increases vascular permeability, and is a potent agonist for mesangial cell contraction. Excessive $\mathrm{LTC}_{4}$ production together with increased oxidative burst $(29,30)$ may contribute to progressive tissue damage in cystinosis. Nevertheless, whether the in vitro increased capability of PMNL from cystinotic children to generate $\mathrm{LTC}_{4}$ participates in the evolution of the disease is presently unknown and thus deserves investigation.

Acknowledgments. The authors thank Dr. J. A. Schneider (Department of Pediatrics, UCSD, La Jolla, CA), who kindly measured intracellular cystine content; Dr. J. Rokach (Merk Frosst, Montreal, Canada), who generously provided the antiserum against $\mathrm{LTC}_{4}$ and synthetic $\mathrm{LTC}_{4}$; Dr. M. Broyer and Dr. C. Loirat, who selected the patients; and N. J. Widmer, who provided excellent secretarial assistance.

\section{REFERENCES}

1. Parker CW 1987 Lipid mediators produced through the lipoxygenase pathway. Ann Rev Immunol 5:65-84

2. Samuelsson B 1983 Leukotrienes: mediators of immediate hypersensitivity reactions and inflammation. Science 220:568-575

3. Hedqvist P, Dahlen SE, Gustafsson L, Hammarstrom S, Samuelsson B 1980 Biological profile of leukotrienes $\mathrm{C}_{4}$ and $\mathrm{D}_{4}$. Acta Physiol Scand 110:331-333

4. Dahlen SE, Bjork J, Hedqvist P, Arfors KE, Hammarstrom S, Lindgren JA, Samuelsson B 1981 Leukotrienes promote plasma leakage and leukocyte 
adhesion in postcapillary venules: in vivo effects with relevance to the acute inflammatory response. Proc Natl Acad Sci USA 78:3887-3891

5. Cramer EB, Pologe L, Pawlowski NA, Cohn ZA, Scott WA 1983 Leukotriene $\mathrm{C}$ promotes prostaglandin synthesis by human endothelial cells. Proc Nat Acad Sci USA 80:4109-4113

6. Feuerstein N, Bash JA, Woody JN, Ramwell PW 1981 Leukotriene C stimulates prostaglandin release from rat peritoneal macrophages. Biochem Biophys Res Commun 100:1085-1090

7. Ford-Hutchinson AW, Bray MA, Doig MF, Shipley ME, Smith MJH 1980 Leukotriene $\mathrm{B}_{4}$, as potent chemokinetic and aggregating substance released from polymorphonuclear leukocytes. Nature 286:264-265

8. Lewis RA, Austen KF 1984 The biologically active leukotrienes: biosynthesis, metabolism, receptors, functions, and pharmacology. J Clin Invest 73:889-897

9. Hammarstrom S 1983 Leukotrienes. Ann Rev Biochem 52:355-377

10. Lee CW, Lewis RA, Corey EJ, Barton A, Oh H, Tauber AI, Austen KF 1982 Oxidative inactivation of leukotriene $\mathrm{C}_{4}$ by stimulated human polymorphonuclear leukocytes. Proc Natl Acad Sci USA 79:4166-4170

11. Schneider JA, Katz B, Melles RB 1990 Update on nephropathic cystinosis. Pediatr Nephrol 4:645-653

12. Gahl WA, Schneider JA, Schulman JD, Thoene JG, Reed GF 1990 Predicted reciprocal serum creatinine at age 10 years as a measure of renal function in children with nephropathic cystinosis treated with oral cysteamine. Pediatr Nephrol 4:129-135

13. Gahl WA, Bashan N, Tietze F, Bernardini I, Schulman JD 1982 Cystine transport is defective in isolated leukocyte lysosomes from patients with cystinosis. Science 217:1263-1265

14. Oshima RG, Rhead WJ, Thoene JG, Schneider JA 1976 Cystine metabolism in human fibroblasts. J Biol Chem 251:4287-4293

15. States B, Segal S 1982 Levels of gamma-glutamyl transpeptidase in cultured skin fibroblasts from cystinotics and normals. Life Sci 27:1985-1990

16. Butler JB, Spielberg SP 1981 Decrease of intracellular cystine content in cystinotic fibroblasts by inhibitors of gamma-glutamyl transpeptidase. J Biol Chem 9:4160-4163

17. Gahl WA, Charnas L, Markello TC, Bernardini I, Ishak KG, Dalakas MC 1992 Parenchymal organ cystine depletion with long-term cysteamine therapy. Biochem Med Metab Biol 48:275-285

18. Gahl WA, Reed GF, Thoene JG, Schulman JD, Rizzo WB, Jonas AJ, Denman DW, Schlesselman JJ, Corden BJ, Schneider JA 1987 Cysteamine therapy for children with nephropathic cystinosis. N Engl J Med 316:971-977
19. Boyum A 1968 Separation of leukocytes from blood and bone marrow. Scand J Clin Lab Invest 21:77-89

20. Steinherz R, Tietze F, Gahl WA, Triche TJ, Chang H, Modesti A, Schulman JD 1982 Cystine accumulation and clearance by normal and cystinotic leukocytes exposed to cystine dimethylester. Proc Natl Acad Sci USA 79:4446-4450

21. Mencia-Huerta JM, Razin E, Ringel EW, Corey EJ, Hoover D, Austen KF, Lewis RA 1983 Immunologic and ionophore-induced generation of leukotriene $\mathrm{B}_{4}$ from mouse bone marrow derived mast cells. J Immunol 130:1885-1890

22. Oshima RG, Willis RC, Furlong CE, Schneider JA 1974 Binding assays for amino acids: the utilization of a cystine binding protein from Escherichia coli for the determination of acid-soluble cystine in small physiological samples. $J$ Biol Chem 249:6033-6039

23. Weller PF, Lee CW, Foster DW, Corey EJ, Austen KF, Lewis RA 1983 Generation and metabolism of 5-lipoxygenase pathway leukotrienes by human eosinophils: predominant production of leukotriene $\mathrm{C}_{4}$. Proc Natl Acad Sci USA 80:7626-7630

24. States B, Lee J, Segal S 1981 Uptake of cystine by cystine-depleted fibroblasts from patients with cystinosis. Biochem Biophys Res Commun 98:290296

25. States B, Harris D, Segal S 1977 Patterns of cystine reduction by fibroblasts from normal and cystinotic children. Pediatr Res 11:685-690

26. Butler JB, Key JD, Hughes BF, Tietze F, Raiford DS, Reed GF, Brannon PM, Spielberg SP, Schulman JD 1987 Glutathione metabolism in normal and cystinotic fibroblasts. Exp Cell Res 172:158-167

27. Jonas AJ, Schneider JA 1982 Plasma cysteamine concentrations in children treated for cystinosis. J Pediatr 100:321-323

28. Greene AA, Marcusson EG, Pintos-Morell G, Schneider JA 1990 Characterization of the lysosomal cystine transport system in mouse L-929 fibroblasts. J Biol Chem 265:9888-9895

29. Pintos-Morell G, Niaudet P, Jean G, Descamps-Latscha B 1985 Altered oxidative metabolism, motility and adherence in phagocytic cells from cystinotic children. Pediatr Res 19:1318-1321

30. Pintos-Morell G, Jean G, Dechaux M, Niaudet P 1991 Increased monocytedependent suppression of polyclonal activation of B lymphocytes from cystinotic children. Pediatr Nephrol 5:597-602

31. Peters-Golden M, Shelly C 1987 Modulation of alveolar macrophage-derived 5-lipoxygenase products by the sulfhydryl reactant, N-ethylmaleimide. J Biol Chem 262:10594-10600

32. Gahl WA, Tietze F 1987 Lysosomal cystine transport in cystinosis variants and their parents. Pediatr Res 21:193-196 